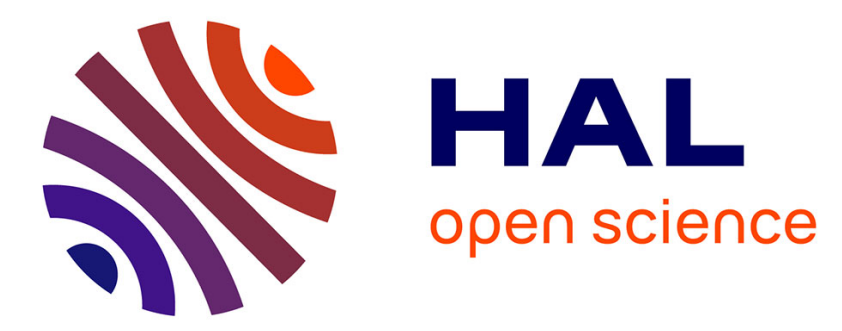

\title{
Novel design of delta winglet pair vortex generator for heat transfer enhancement
}

Mohammad Oneissi, Charbel Habchi, Serge Russeil, Daniel Bougeard, Thierry Lemenand

\section{- To cite this version:}

Mohammad Oneissi, Charbel Habchi, Serge Russeil, Daniel Bougeard, Thierry Lemenand. Novel design of delta winglet pair vortex generator for heat transfer enhancement. International Journal of Thermal Sciences, 2016, 109, pp.1-9. 10.1016/j.ijthermalsci.2016.05.025 . hal-02525540

\section{HAL Id: hal-02525540 \\ https://univ-angers.hal.science/hal-02525540}

Submitted on 31 Mar 2020

HAL is a multi-disciplinary open access archive for the deposit and dissemination of scientific research documents, whether they are published or not. The documents may come from teaching and research institutions in France or abroad, or from public or private research centers.
L'archive ouverte pluridisciplinaire HAL, est destinée au dépôt et à la diffusion de documents scientifiques de niveau recherche, publiés ou non, émanant des établissements d'enseignement et de recherche français ou étrangers, des laboratoires publics ou privés. 


\title{
Novel design of delta winglet pair vortex generator for heat transfer enhancement
}

\author{
Mohammad Oneissi a, b, c, Charbel Habchi ${ }^{\mathrm{d}}$, Serge Russeil ${ }^{\mathrm{b}, ~}{ }^{\text {* }}$, Daniel Bougeard ${ }^{\mathrm{b}}$, \\ Thierry Lemenand ${ }^{c}$ \\ a Lebanese International University, Mechanical Engineering Department, Beirut, Lebanon \\ b Mines Douai, EI, F59500, Douai, France \\ c Angers University, ISTIA, LARIS EA 7315, 49000, Angers, France \\ ${ }^{\mathrm{d}}$ Notre Dame University - Louaize, Mechanical Engineering Department, P.O. Box: 72, Zouk Mikael, Zouk Mosbeh, Lebanon
}

\section{A R T I C L E I N F O}

\section{Article history:}

Received 22 August 2015

Received in revised form 22 May 2016

Accepted 24 May 2016

Available online 2 June 2016

\section{Keywords:}

Heat transfer enhancement

Winglet pair

Vortex generator

Plate-fin heat exchanger

Parallel-plate channel

Numerical simulation

\begin{abstract}
A B S T R A C T
Heat transfer is a naturally occurring phenomenon that can be greatly enhanced with the aid of vortex generators (VG). Three-dimensional numerical simulations of longitudinal vortex generators are performed to analyze heat transfer enhancement in parallel plate-fin heat exchanger. The shear-stress transport (SST) $k-\omega$ model is adopted to model the flow turbulence. Empirical correlations from the open literature are used to validate empty channel simulations. First, numerical simulations are conducted for the classical delta winglet pair (DWP) which is introduced as the reference case in this study. Then, an innovative VG configuration, named inclined projected winglet pair (IPWP), is examined and it shows superior performance relative to the DWP. The IPWP exhibits similar heat transfer rates than that of the DWP but with lower pressure drop penalty due to its special aerodynamic design. The local performance is analyzed based on the streamwise distribution of Nusselt number and friction coefficient criteria in addition to vorticity. This study highlights the different mechanisms involved in the convective heat transfer intensification by generating more vortices using more aerodynamic VG shape while decreasing the pressure drop penalty.
\end{abstract}

๑) 2016 Elsevier Masson SAS. All rights reserved.

\section{Introduction}

The use of vortex generators (VG) in the various industrial fields is widespread ranging from compact heat exchangers to aeronautics [1-4]. In the field of heat exchangers, the role of the VG is the enhancement of the heat exchange process between the wall and the working fluid. This enhancement relies on generating a secondary flow in form of complex streamwise and transverse vortices. The vortices disrupt the growth of the boundary layer and eventually serve in enhancing the heat transfer [5]. For this intention, two enhancement methods can be implemented: the active VG method and the passive VG method [6]. Passive VG are more commonly used since they are characterized by their efficiency, economy, manufacturing simplicity and maintenance ease, opposite to active VG which are energy consumers and less easy to

\footnotetext{
* Corresponding author. DEI, Mines Douai, 941 rue Charles Bourseul, BP 10838, 59508 Douai Cedex, France. Tel.: +33 0327712388

E-mail address: serge.russeil@mines-douai.fr (S. Russeil).
}

implement. These VG have various types which include helical and twisted inserts $[7,8]$, dimples or protrusions [9,10], cylindrical tubes [11-14], transverse vortex generators (TVG) [10,15,16], longitudinal vortex generators (LVG) [17-23], plane or curved surface of VG [24,25] or a combination of the above types [10,22,26-29].

Transverse vortices are two-dimensional flows with axes normal to the flow direction, while longitudinal vortices rotate about an axis in the streamwise direction, implying a threedimensional swirling flow. When pressure losses are taken into account, LVG are found to have an advantage over TVG in terms of global mixing and heat transfer performances [30].

This paper focuses on the study of LVG and their unique capability in heat transfer enhancement through the generation of large scale longitudinal vortices. This enhancement is a result of the combination of the main mechanisms of heat transfer intensification: the reduction of the laminar sub layer thickness near the wall, the development of three-dimensional turbulent layers and the swirl motion of the streamwise vortices that enhances convective transfer [31,32]. 


\begin{tabular}{|c|c|c|c|}
\hline \multicolumn{2}{|c|}{ Nomenclature } & $T_{S}$ & surface temperature, $\mathrm{K}$ \\
\hline$A$ & cross-sectional area & $u$ & flow velocity in $x$ direction, $\mathrm{m} \mathrm{s}^{-1}$ \\
\hline$B$ & channel width, $\mathrm{m}$ & $v$ & flow velocity in $y$ direction, $\mathrm{m} \mathrm{s}^{-1}$ \\
\hline$C_{p}$ & specific heat at constant pressure, $\mathrm{J}(\mathrm{kgK})^{-1}$ & $w$ & flow velocity in $z$ direction, $\mathrm{m} \mathrm{s}^{-1}$ \\
\hline$D_{h}$ & hydraulic diameter, $\mathrm{m}$ & $x_{v}$ & distance of wingtips from the channel entrance, $\mathrm{m}$ \\
\hline$f$ & Fanning friction factor, dimensionless & $z$ & Vortex generator height, m \\
\hline$H$ & channel height, m & & \\
\hline$h$ & convective heat transfer coefficient, $\mathrm{W}\left(\mathrm{m}^{2} \mathrm{~K}\right)^{-1}$ & \multicolumn{2}{|c|}{ Greek letters } \\
\hline$j$ & Colburn factor, dimensionless & $\mu$ & dynamic viscosity, Pa s \\
\hline$k$ & thermal conductivity, $\mathrm{W}(\mathrm{mK})^{-1}$ & $\nu$ & kinematic viscosity, $\mathrm{m}^{2} \mathrm{~s}^{-1}$ \\
\hline$L$ & channel length, $\mathrm{m}$ & $\rho$ & fluid density, $\mathrm{kg} \mathrm{m}^{-3}$ \\
\hline$l$ & Vortex generator span, $\mathrm{m}$ & $\beta$ & angle of attack, ${ }^{\circ}$ \\
\hline$\dot{m}$ & mass flow rate, $\mathrm{kg} \mathrm{s}^{-1}$ & & \\
\hline $\mathrm{Nu}$ & Nusselt number, dimensionless & \multicolumn{2}{|c|}{ Abbreviations } \\
\hline $\mathrm{Pe}$ & Péclet number $=R e P r$, dimensionless & $V G$ & Vortex Generator \\
\hline Po & Poiseuille number, dimensionless & $D W P$ & Delta Winglet Pair \\
\hline $\operatorname{Pr}$ & Prandtl number, dimensionless & $R W P$ & Rectangular Winglet Pair \\
\hline$\Delta P$ & pressure drop, $\mathrm{Pa}$ & $I P W P$ & Inclined Projected Winglet Pair \\
\hline$q^{\prime \prime}$ & heat flux & $L V G$ & Longitudinal Vortex Generator \\
\hline $\operatorname{Re}$ & Reynolds number, dimensionless & TVG & Transverse Vortex Generator \\
\hline$s$ & distance between tips of winglet pair, $\mathrm{m}$ & CFD & Computational Fluid Dynamics \\
\hline$T_{b, x}$ & bulk temperature at position $x, \mathrm{~K}$ & SST & Shear-Stress Transport \\
\hline$T_{i}$ & inlet temperature, $\mathrm{K}$ & $T E F$ & Thermal Enhancement Fraction, dimensionless \\
\hline$T_{o}$ & outlet bulk temperature, $\mathrm{K}$ & & \\
\hline
\end{tabular}

Winglet pairs exist in two configurations, one is the common flow-down and the other is the common flow-up. When the transverse distance between leading edges is less than that of trailing edges, the configuration is known as common flow-down and vice-versa [33]. Common flow-down vortices create downwash in between, and up-wash flow in the outside regions. Along the streamwise direction, the vortices' velocity vectors decrease while the distance between vortex cores increases which leads to the thinning of the thermal boundary layer [33]. Tian et al. [34] compared delta-winglet pair (DWP) with rectangular winglet pair (RWP) for common flow-down and common flow-up configurations and deduced that DWP in common flow-down geometry is more efficient than other configurations. Biswas et al. [5] studied the performance of a delta winglet type VG and concluded that such VGs show great promise for enhancing the heat transfer in plate-fin heat exchangers. Meanwhile, common flow-up configuration also seems to be important to study as future work in some applications. In fact, Jain et al. [35] proposed a common flow-up configuration delta winglet that causes significant separation delay, reduced form drag and removes the zones of poor heat transfer.

The present work focuses on designing a better aerodynamic VG shape that can provide the same heat transfer with a reduced pressure drop when compared to the DWP as a reference case. The new VG increases the global thermal enhancement with an average of about $6 \%$ and the averaged global pressure drop decreases by about $10 \%$ over a wide range of Reynolds numbers. Moreover, the effect of the new VG geometry on the flow structure and thus on the heat transfer mechanism is analyzed.

The numerical method, computational domain and mesh sensitivity analysis are presented in the problem statement in section 2. Numerical validation, global performance followed by local examination of the heat transfer phenomena and compactness comparison are discussed in section 3. Finally, section 4 is devoted to the concluding remarks.

\section{Problem statement}

\subsection{Numerical model}

The flow field is governed by the three-dimensional (3D) steady-state Reynolds averaged Navier-Stokes (RANS) equations. The continuity and momentum equations for an incompressible Newtonian fluid are:

$\frac{\partial u_{i}}{\partial x_{i}}=0$

$u_{j} \frac{\partial u_{i}}{\partial x_{j}}=-\frac{1}{\rho} \frac{\partial p}{\partial x_{i}}+v \frac{\partial_{u_{i}}^{2}}{\partial x_{j} \partial x_{j}}-\frac{\partial \overline{u_{i}^{\prime} u_{j}^{\prime}}}{\partial x_{j}}$

where the term $-u_{i}^{\prime} u_{j}^{\prime}$ is the Reynolds stress tensor resulting from the averaging procedure on the nonlinear convective terms in the momentum equations.

The heat transfer is governed by the energy equation given below:

$\frac{\partial}{\partial x_{i}}\left[u_{i}(\rho E+p)\right]=\frac{\partial}{\partial x_{i}}\left(\lambda_{e f f} \frac{\partial T}{\partial x_{i}}\right)$

where $E$ is the total energy and $\lambda_{\text {eff }}$ the effective thermal conductivity.

The solver used for the flow computation is the ANSYS Fluent 15, which is based on an Eulerian approach to solve the Cauchy equations through cell-centered finite volume discretization [10]. The code computes the conservation equations for mass and momentum in addition to the energy equation [36]. Turbulence models allow the calculation of the mean flow without first calculating the full time-dependent flow field.

In this study, for laminar flows $(R e=270,540$ and 1080) the laminar model is used whereas for turbulent flows ( $R e=2800$, 
$4600,7700,10,800,16,200,21,600$ and 30,000$)$ the shear-stress transport (SST) $\kappa-\omega$ model developed by Menter [37] is used. This turbulence model solves two additional partial differential equations; a modified version of the turbulence kinetic energy equation $\kappa$ used in $\kappa-\varepsilon$ model and a transport equation for the specific dissipation $\omega$. Also, the shear stress transport (SST) combines the use of $\kappa-\omega$ formulation in the inner parts of the boundary layer and the switching to a $\kappa-\varepsilon$ behavior in the free-stream thus avoiding the $\kappa-\omega$ sensitivity to the inlet free-stream turbulence properties. In addition, this model is characterized by its good behavior in adverse pressure gradients and separating flows while attaining accuracy and reliability [38].

The preceding attributes give the SST $\kappa-\omega$ model additional accuracy and reliability thus providing an advantage over the standard $\kappa-\omega$ model. Moreover, the SST $\kappa-\omega$ model was used by several researchers in previous works and it shows a fair agreement with experimental results for flow configurations similar to the present study $[39,40]$.

The use of the SST $\kappa-\omega$ model necessitates assessment of the wall adjacent cell size analogous to the dimensionless wall distance $y^{+}$ less than 4 , ensuring that the viscous sublayer is meshed.

The SST $\kappa-\omega$ model transport equations are:

$\rho \frac{\partial}{\partial x_{i}}\left(k u_{i}\right)=\frac{\partial}{\partial x_{j}}\left(\Gamma_{k} \frac{\partial k}{\partial x_{j}}\right)+\tilde{G}_{k}-Y_{k}$

$\rho \frac{\partial}{\partial x_{i}}\left(\omega u_{i}\right)=\frac{\partial}{\partial x_{j}}\left(\Gamma_{\omega} \frac{\partial \omega}{\partial x_{j}}\right)+G_{\omega}-Y_{\omega}+D_{\omega}$

where

$\tilde{G}_{k}$ is the production of turbulence kinetic energy due to mean velocity gradients,

$G_{\omega}$ is the generation of $\omega$,

$\Gamma_{k}$ is the effective diffusivity of $\kappa ;\left(\Gamma_{k}=\mu+\frac{\mu_{t}}{\sigma_{k}}\right)$,

$\Gamma_{\omega}$ is the effective diffusivity of $\omega ;\left(\Gamma_{\omega}=\mu+\frac{\mu_{t}}{\sigma_{\omega}}\right)$,

$Y_{k}$ is the dissipation of $\kappa$ due to turbulence,

$Y_{\omega}$ is the dissipation of $\omega$ due to turbulence,

$D_{\omega}$ is the cross-diffusion,

$\sigma_{k}, \sigma_{\omega}$ is the turbulent Prandtl number for $\kappa$ and $\omega$ respectively, and

$\mu_{t}$ is the turbulent viscosity

For detailed discussion of these equations refer to the ANSYS Fluent 15.0 theory guide [38].

For spatial discretization of the convective terms, a scheme of double precision and second order upwind is used to consecutively solve the flow equations [41]. Central-difference and second order accuracy are selected for the diffusion terms. The Coupled algorithm is used for the pressure-velocity coupling with the pseudo transient option. Pseudo transient method option is a form of implicit under-relaxation for steady-state cases. It allows the user to obtain solutions faster and more robustly.

\subsection{Computational domain}

The channel dimensions used for the simulations are taken from a previously designed parallel plate channel with height $H$, breadth $B=1.6 H$ and of length $L=13 H$. An isometric view showing the boundary conditions is presented in Fig. 1.

The Reynolds number is calculated based on the hydraulic diameter $D_{h}=2 H$. A hydrodynamic and thermally developing flow is computed with a uniform inlet velocity profile and uniform inlet temperature equal to $300 \mathrm{~K}$ for a wide range of Reynolds numbers: $270,540,1080,2800,4600,7700,10,800,16,200,21,600$ and
30,000. The Reynolds number variation is done by varying the mean flow velocity magnitude at the inlet. For the outlet, a constant pressure outlet condition has been set with a zero gauge pressure. Isothermal walls are set for both, upper and bottom walls, with a constant temperature of $350 \mathrm{~K}$. All VG cases have been simulated as an adiabatic wall to highlight the effect of the flow structure on the convective heat transfer alone. For turbulent cases, the turbulence intensity on the inlet boundary has a dramatic influence on local and global results. Proper turbulence intensity has to be chosen and in this study, turbulence intensity equal to $3 \%$ is selected. This value is in the range of the moderate wind tunnel intensities $(1 \%-5 \%)$ [42]. Also, the turbulence length scale, taken as a fraction of the inlet hydraulic diameter $D_{h}[43,44]$, can be chosen equal to $0.07 D_{h}$ as used in similar flow configurations [45] or choosing the turbulence intensity with the hydraulic diameter is also valid and gives same results.

The goal behind this study is to improve or at least maintain the heat enhancement while reducing pressure drop induced by the DWP ( $90^{\circ}$ elevation angle with the bottom wall). Therefore, the same frontal area as that of the DWP is preserved but with an inclination angle relative to the channel wall. A downstream projection on a $30^{\circ}$ inclined plane from the DWP bottom edge is depicted. To state the matter differently, if the DWP surface was inclined $30^{\circ}$ about the lower edge and then an extrusion of the DWP is made in the downstream direction, then the result is an inclined projected winglet pair (IPWP). Fig. 2 shows the 2D geometry of the IPWP generated by the projection of the DWP contour profile and the 3D model of the IPWP is shown in Fig. 3.

\subsection{Mesh sensitivity}

Non-uniform mesh with polyhedral cells is used for the computational domain. In order to maintain an accepted low value for $y^{+}$, all solid walls in the channel (fin walls and VG) are treated with 10 inflation layers with a first layer thickness of $40 \mu \mathrm{m}$. Mesh independency tests are carried out on an empty channel turbulent flow for the highest Reynolds number $R e=21,600$.

Table 1 shows the model mesh configurations and sensitivity scheme respectively. In order to reach the mesh size adapted in the simulation, an arbitrary estimate of the size is implemented and then simulated. In the inflation column, the first number gives the first inflation layer thickness, while the second gives the number of inflation layers. The element size is then decreased by a factor of 1.30 until the error based on both global Nusselt number and friction coefficient is less than $2 \%$. Thus, as it can be seen from Table 1 , Mesh-4 is used for all the other simulations. This choice is due to the non-necessity of any further refinement since the error becomes smaller than $2 \%$ with this mesh. The $y^{+}$for all of the cases has a value smaller than 2 .

\section{Numerical results and discussion}

\subsection{Numerical validation}

Developing flow (velocity and temperature) case is simulated in the present work by applying uniform velocity and temperature profiles at the inlet boundary condition. The performance evaluation of the different configurations is divided into two main categories: global and local approaches.

Global Nusselt number is given by:

$\overline{N u}=\frac{D_{h} h}{k}=\frac{2 H h}{k}$

where: 


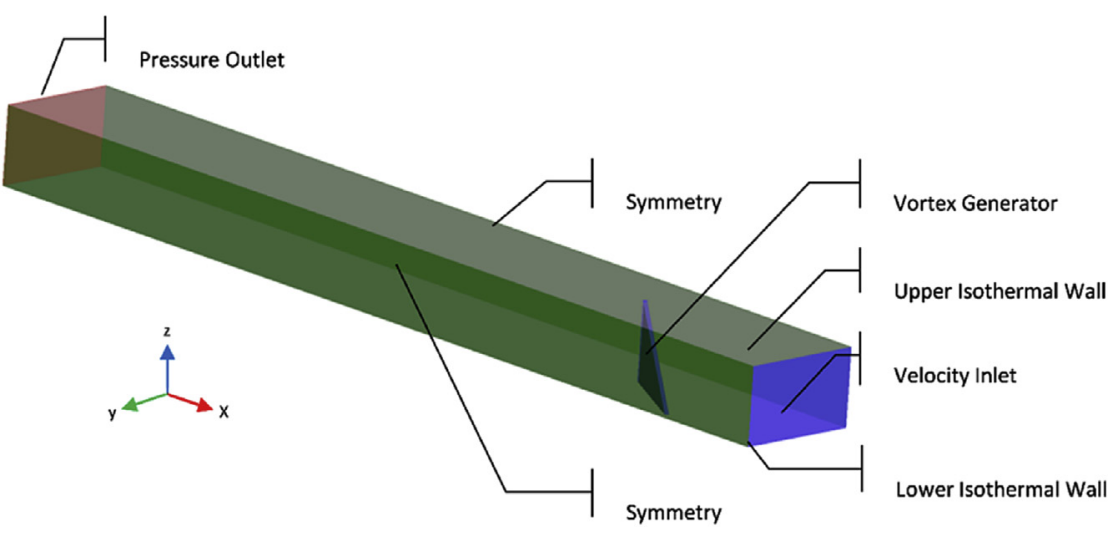

Fig. 1. Isometric view of the computational domain showing the boundary conditions.

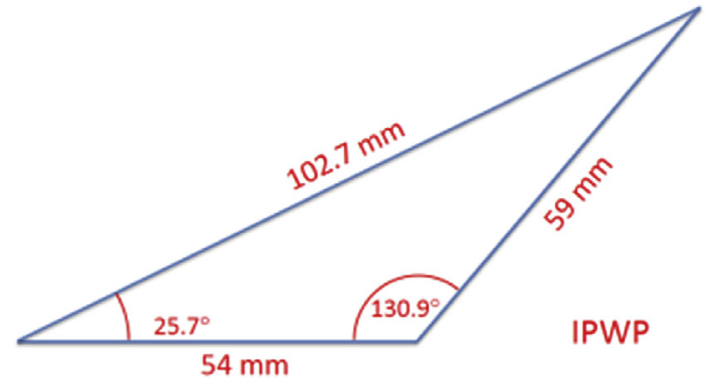

Fig. 2. 2D dimensions of the IPWP vortex generator.

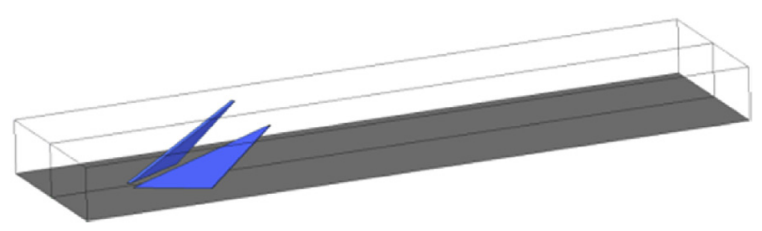

Fig. 3. 3D model of the IPWP vortex generator.
$T E F=\frac{N u}{N u_{0}}\left(\frac{f}{f_{0}}\right)^{-\frac{1}{3}}$

where the index " 0 " is for the case of empty channel.

Local Nusselt number at a given streamwise location $x$ in the channel is given by:

$N u_{x}=\frac{D_{h} h_{x}}{k}=\frac{2 H q_{x}^{\prime \prime}}{k\left(T_{s}-T_{x, b}\right)}$

where:

$T_{x, b}=\frac{\int_{A} \rho u C_{p} T d A}{\dot{m} C_{p}}=\frac{\int_{A} \rho u C_{p} T d A}{\rho u C_{p} d A}=\frac{1}{U A} \int_{A} u T d A$

Local friction at a given streamwise location $x$ in the channel is given by:

Table 1

Mesh study information.

\begin{tabular}{|c|c|c|c|c|c|c|}
\hline Mesh & Maximum element size (mm) & Wall sizing (mm) & Number of elements & Inflation (mm) & Maximum $y^{+}$ & $\mathrm{Nu}$ error $(\%)$ \\
\hline 1 & 3 & 2 & 276,321 & $10 \mu \mathrm{m}-20 \mathrm{~L}$ & 1.55 & - \\
\hline 2 & 2.3 & 1.5 & 439,539 & $20 \mu \mathrm{m}-18 \mathrm{~L}$ & 0.94 & 5.95 \\
\hline 3 & 1.7 & 1.15 & 713,156 & $30 \mu \mathrm{m}-12 \mathrm{~L}$ & 0.92 & 3.13 \\
\hline 4 & 1.3 & 0.9 & $1,299,018$ & $40 \mu \mathrm{m}-10 \mathrm{~L}$ & 0.82 & 1.17 \\
\hline
\end{tabular}

$h=\frac{\dot{m} C_{p}\left(T_{o}-T_{i n}\right)}{A_{f}\left(T_{s}-T_{a v g}\right)}$

and

$T_{\text {avg }}=\frac{T_{o}+T_{\text {in }}}{2}$

Global friction factor is given by:

$f=\frac{D_{h} \Delta P}{2 L \rho U^{2}}=\frac{H \Delta P}{L \rho U^{2}}$

where the pressure $P$ is averaged over the flow cross section.

The thermal enhancement factor (TEF) is given by:
$f_{x}=\frac{\Delta P}{P_{\text {dynamic }}}=\frac{2\left(P_{\text {in }}-P_{x}\right)}{\rho U^{2}}$

For thermally and hydraulically developing laminar air flow, the results are validated for global Nusselt number using Stephan correlation [46], which is the integration of the local Nusselt number $\left(N u_{x}\right)$ on the channel length based on the bulk temperature at each position $T_{x, b}$. This correlation is valid in the range $0.1 \leq \operatorname{Pr} \leq$ 1,000 for parallel plate channels.

The local Nusselt number is given by:

$N u=\frac{D_{h} h}{k}=\frac{2 H \cdot q^{\prime \prime}}{k\left(T_{s}-T_{x, b}\right)}$ 
where $q^{\prime \prime}$ is the heat flux at position $x$ and

$T_{b}=\frac{1}{U \cdot A} \int_{A} u \cdot T \cdot d A$

$N u_{0-x}=\frac{1}{x} \int_{0}^{x} N u_{(x)} \cdot d x$

$N u_{0-x}=7.55+\frac{0.024 x_{*} *^{-1.14}}{1+0.0358 x^{-0.64} \operatorname{Pr}^{0.17}}$

where

$x *=\frac{x}{P e \cdot D_{h}}=\frac{x}{R e_{D_{h}} \cdot \operatorname{Pr} \cdot D_{h}}$

Local Nusselt number is expressed by the following analytical correlation based on the bulk temperature [46]:

$N u_{x}=7.55+0.024 \frac{0.0179 x^{-1.78} \operatorname{Pr}^{0.17}-0.14 x_{*}-1.14}{\left[1+0.0358 x_{*} *^{-0.64} \mathrm{Pr}^{0.17}\right]^{2}}$

The relation that combines the Nusselt number based on the bulk temperature $\left(N u_{x}\right)$ and the one based on the entrance temperature can be set as:

$N u_{e(x)}=N u_{x} e^{-\frac{k N u_{x}}{D_{h} \cdot \dot{m} c_{p}} z}$

Table 2 shows the global Nusselt numbers obtained from simulation compared to Stephan correlation [46] in laminar flow cases studied in this work. It shows that the Nusselt numbers obtained by simulation agrees fairly with that obtained by Stephan's correlation for laminar flow case.

A second approach is also adopted to validate the numerical results with those obtained experimentally by Tiggelbeck's experimental [47]. The results of interest are those dealing with a delta winglet pair (DWP) normalized to an empty channel. Tiggelbeck et al. [47] in their experiments found that the values of the normalized global Nusselt number and friction factor for $R e=4600$ are equal to 1.49 and 1.91 respectively. Table 3 shows a comparison between numerical simulation and experimental results obtained by Tiggelbeck et al. [47] at $R e=4600$. The last term corresponds to the thermal enhancement factor. The results are in a good agreement with each other with relatively low discrepancy and the numerical model seems reliable to predict flow and heat transfer characteristics.

\subsection{Global performance analysis of vortex enhanced configurations}

Fig. 4 plots the thermal enhancement factor for both IPWP and DWP configurations. This figure shows that the IPWP performance is always better than the DWP over the whole range of Reynolds numbers. For laminar flow the enhancement is relatively low (about 2\%), while the enhancement is greater (about 6\%) in the turbulent flow especially in the range of moderate Reynolds
Table 3

Normalized global Nusselt number, friction factor and thermal enhancement factor comparison between numerical simulation and experimental results at $R e=4600$.

\begin{tabular}{llll}
\hline & Experiment & Simulation & Error (\%) \\
\hline $\mathrm{Nu} / \mathrm{Nu} u_{0}$ & 1.49 & 1.56 & 4.69 \\
$f / f_{0}$ & 1.91 & 1.95 & 2.09 \\
$\left(\mathrm{Nu} / \mathrm{Nu} u_{0}\right)\left(f / f_{0}\right)^{-1 / 3}$ & 1.2 & 1.25 & 4.17 \\
\hline
\end{tabular}

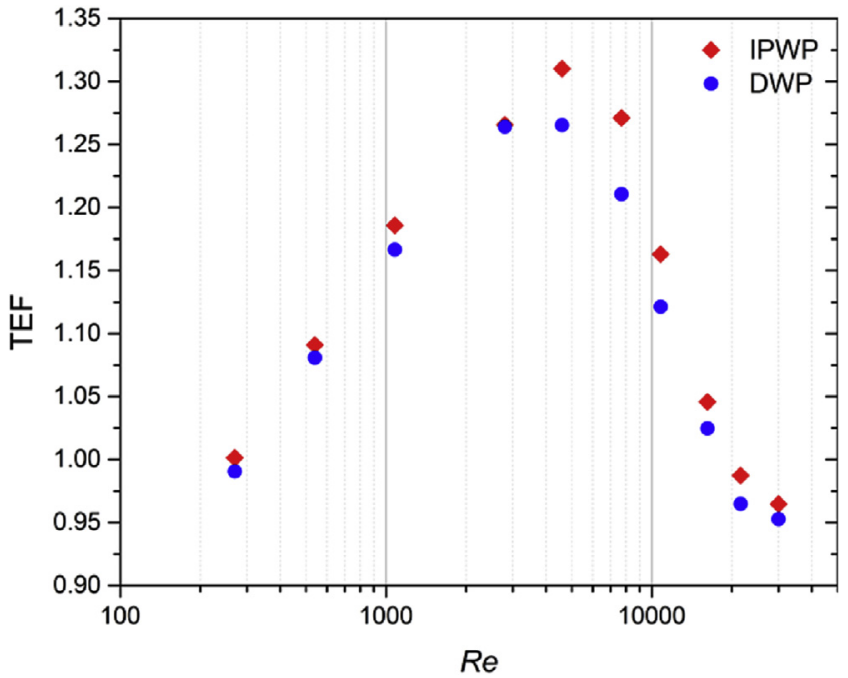

Fig. 4. Thermal enhancement factor (TEF) for DWP and IPWP configurations of vortex generator.

numbers between 4600 and 10,800 .

This behavior is related to the difference in the local flow structures generated by the VGs at the different Reynolds numbers. For this aim, a detailed local analysis of the flow and heat transfer is conducted in the next section.

\subsection{Local performance analysis}

Subsequent to demonstrating the performance of the IPWP on the global scale, this section illustrates the performance from a local point of view. One case is discussed here, corresponding to a $R e=4,600$, as Tiggelbeck et al. [47] experiment to understand the flow characteristics and to give an explanation of the heat transfer mechanisms.

Fig. 5 shows the streamwise evolution of the spanwise-averaged Nusselt number throughout the channel (see equation (11)). Friction coefficient and vorticity are illustrated respectively in Figs. 6 and 7. The left vertical dotted line with a filled triangle at the bottom of the graph represents the VG leading edge location connected to the bottom wall. The middle one designate for the separation of the bottom trailing edge with the bottom wall while the last vertical line represents the position where the IPWP vortex generator trailing edge separates from the upper wall.

Regarding the local Nusselt number behavior shown in Fig. 5, the IPWP local Nusselt number acts in an oscillatory manner on the

Table 2

Global Nusselt number comparison between simulation and correlations in the case of laminar flow.

\begin{tabular}{|c|c|c|c|}
\hline Reynolds number $R e$ & Nusselt number $\mathrm{Nu}$ & Stephan's correlation [46] & Error $(\%)$ \\
\hline 270 & 7.85 & 8.42 & 6.78 \\
\hline 540 & 9.41 & 9.26 & 1.62 \\
\hline 1080 & 11.58 & 10.78 & 7.41 \\
\hline
\end{tabular}




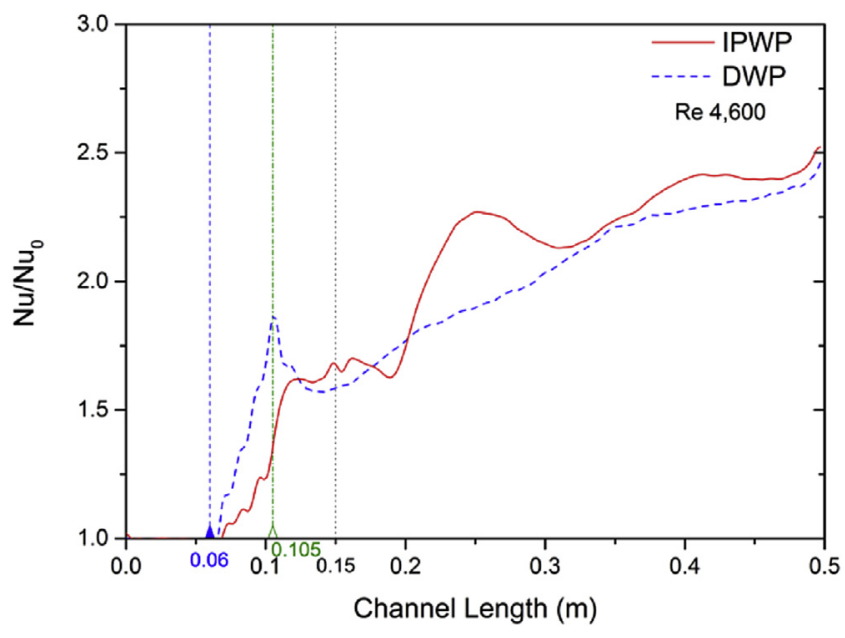

Fig. 5. Normalized local Nusselt number for the IPWP and DWP configurations.

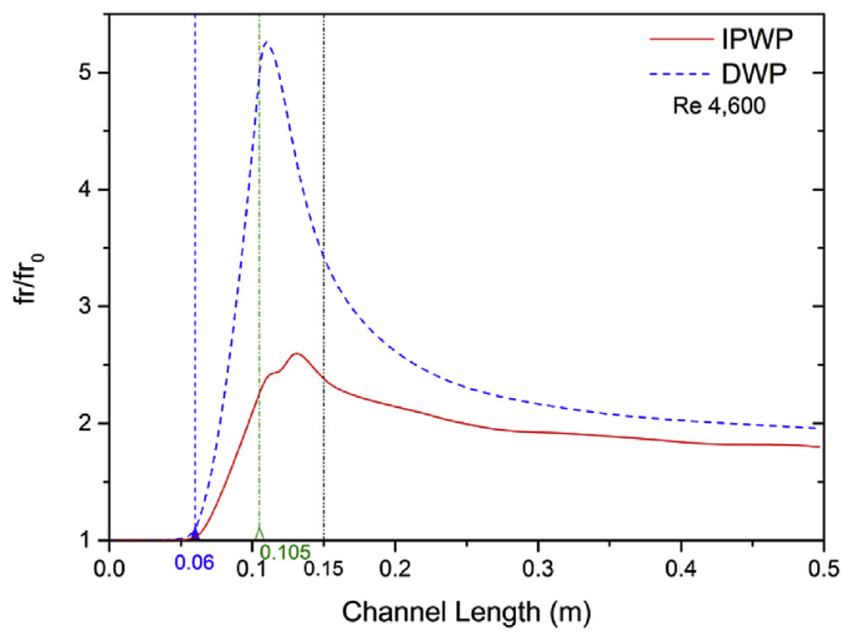

Fig. 6. Normalized local friction coefficient for the IPWP and DWP configurations.

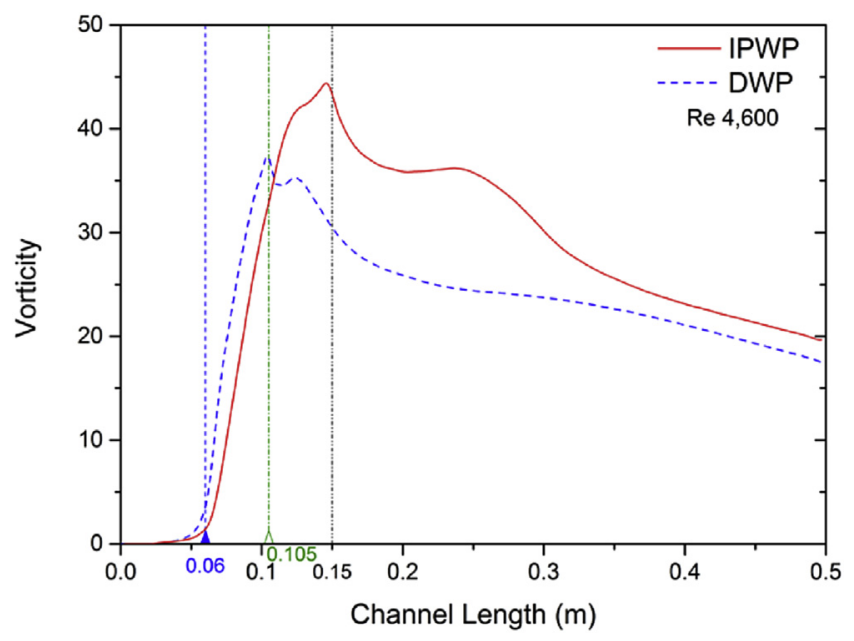

Fig. 7. Vorticity generated by the IPWP and DWP configurations.

contrary of DWP Nusselt number that runs smoothly monotonic downstream the VG. This non-trivial behavior is due to the generation of several complex induced vortices in addition to the phenomena of moving vortex center across the channel that causes a complex interaction among vortices. Further explanation of this phenomenon is described in the next section. The local $\mathrm{Nu}$ in the IPWP is less than that of the DWP upstream the location of the VG but it gets greater than the DWP in the downstream region.

The normalized friction coefficient decreases from a value of 5.25 for a DWP vortex generator to 2.55 for IPWP one. This large decrease in the local friction coefficient is due to the inclination of the new VG configuration that decreases the pressure drop in the flow all along the channel. In addition to the superior performance of the IPWP from the friction point of view, Fig. 7 shows the better production of vorticity for the IPWP configuration over the DWP one. The vorticity produced from the IPWP is slightly lower upstream the VG but it is greatly enhanced in the downstream direction all along the channel, similarly to what has been observed for the local Nusselt number.

To summarize, based on local Nusselt number criterion, both configurations pertain to relatively similar values as shown in Fig. 5 with a small enhancement induced by the IPWP. Fig. 6 illustrates the local friction coefficient of the IPWP compared to the DWP. It's noticeable that the peak in the friction coefficient of the DWP is diminished by about 50\% when compared to the IPWP. Moreover, Fig. 7 shows around 30\% vorticity increase in the IPWP configuration with respect to the DWP. These better performances of the IPWP vortex generator over others necessitates a deep and detailed analysis of the heat transfer mechanism as discussed in the following section.

\subsection{Flow structure and temperature distribution}

For thorough examination of the occurring flow and heat transfer mechanisms, cross section planes are made to show the various streamlines and contours in different locations. Fig. 8 shows velocity streamlines and $\lambda_{2}$ contours at different planes for the DWP and IPWP configurations. The concept of $\lambda_{2}$ appeared when Jeong and Hussain [48] propose that a vortex corresponds to a region where two eigenvalues of the symmetric part of the square of the velocity gradient are negative. For further details regarding the identification of a vortex criterion $\left(\lambda_{2}\right)$, reader may refer to Jeong and Hussain [48].

What is surprising from Fig. 8 is the fact that the IPWP generates more streamwise vortical flow structures than the DWP does. Also Fig. 8 enables to highlight the vortices location inside the channel for the IPWP. The increase in the number of streamwise vortices explains the increase in the Nusselt number and in the streamwise vorticity since more fluid particles are ejected from the near wall regions to the flow core.

For a detailed analysis, let's consider first the development of the vortices generated from a DWP vortex generator inside a parallel plate heat exchanger as presented in Fig. 9. Three vortices for a single VG are generated: a main vortex (a) is generated from the downstream fluid flow over the DWP vortex generator, a corner vortex (b) is developed after reaching the VG bottom trailing edge, and the third secondary vortex (c) is resulted due to the induced viscous force.

Fig. 10 illustrates the generation mechanism of the vortices for the IPWP configuration. A main clock-wise vortex (a) is generated from the downstream fluid flow over the sloped edge of the IPWP vortex generator. The VG base edge separates from the bottom wall of the heat exchanger first, thus producing a bottom counter clockwise corner vortex (b). When moving downstream, the top edge of the VG separates from the upper wall leading for the generation of the upper counter clock-wise corner vortex (c). Two secondary vortices (d) and (e) are generated due to the induced viscous force 


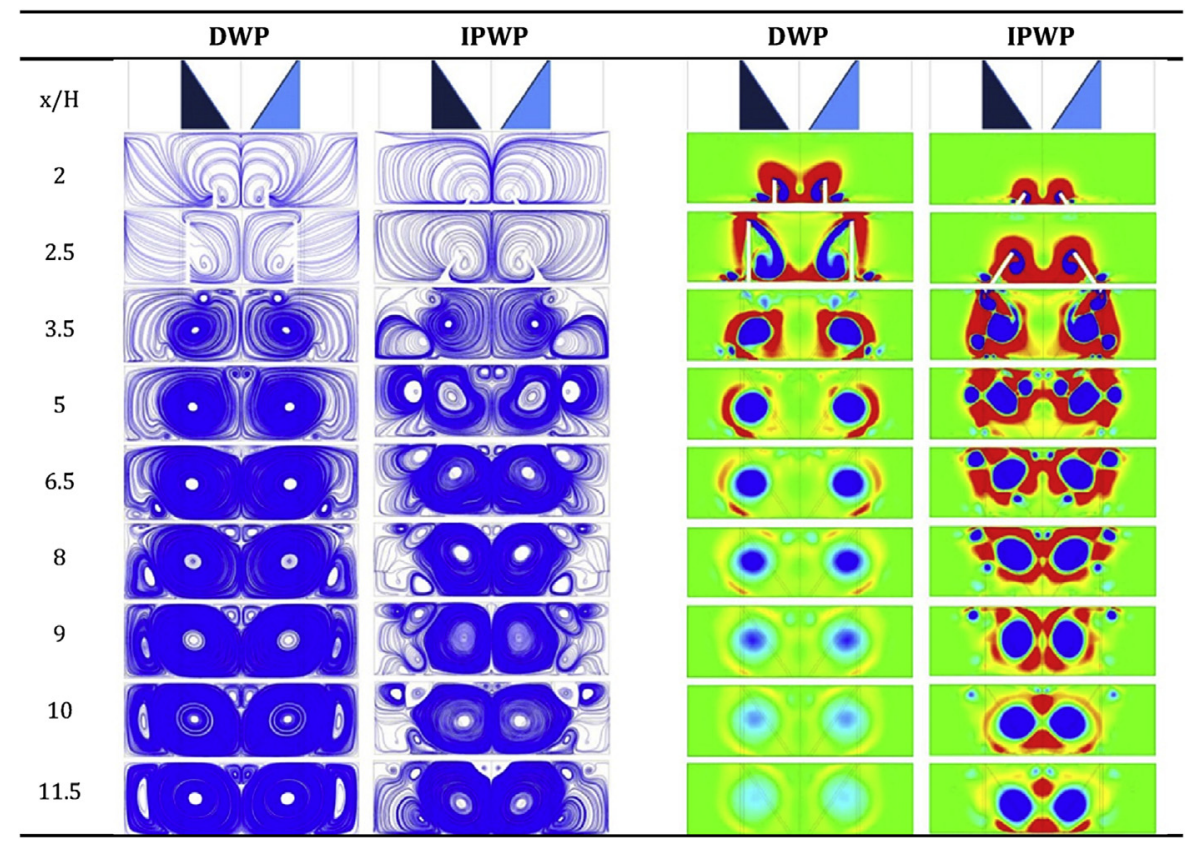

Fig. 8. Velocity streamlines (left) and $\lambda_{2}$ contours (right) for the DWP and IPWP configurations at different section planes.

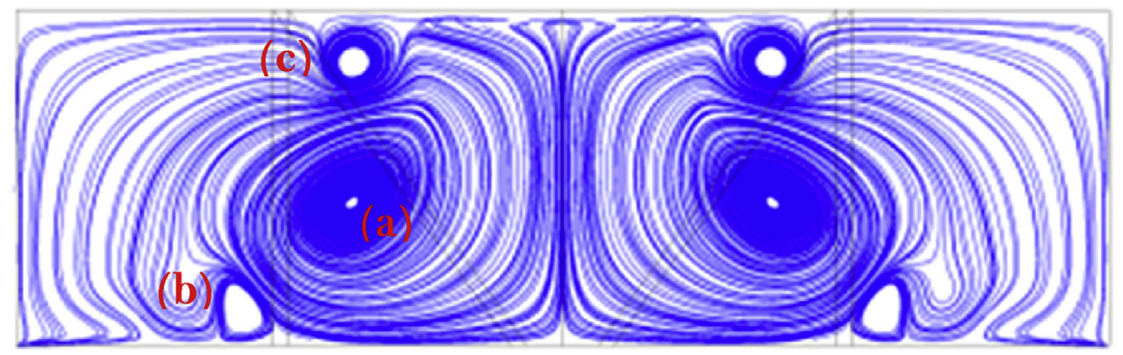

Fig. 9. Vortices developing mechanism from the DWP configuration at $x / H=3.5$ from the inlet.

of the primary vortices. One vortex (d) that rotates in the counter clock-wise direction is developed at the bottom surface and the other (e) at the upper one of the channel spins in the clock-wise direction. The change in vortex center location of the vortices (b) and (c) is established due to the swirl flow of vortex (a). This displacement of the vortices centers is due to the fluid viscous interaction with the main vortex flow. The viscous interaction force moves the center of small vortices in the direction of swirl flow, thus we can see that the centers of vortices (b) and (c) moves in the clockwise direction.

Fig. 8 also shows that the IPWP corner vortex (b) appears earlier than that for DWP but the main difference is that its size grows a lot while it moves towards the mid height of the channel and then towards the upper wall. While for the DWP case, the corner vortex (b) dissipates quite rapidly downstream when compared to the IPWP configuration. This is due to the difference in VG length where IPWP extends to a longer distance that DWP configuration does.

\section{Conclusion}

Three-dimensional numerical simulations of two configurations of vortex generators are performed to analyze heat transfer enhancement in parallel plate-fin heat exchanger. Laminar flow is simulated for Reynolds numbers 270, 540 and 1080. Turbulent flow with the aid of the $\kappa-\omega$ SST model is modeled and validated with correlations and experimental data. The DWP configuration of Tiggelbeck et al. [47] is built-up on and used to validate the results obtained through simulations. The aim of this work is to produce a more aerodynamic configuration that reduces pressure drop and enhances heat transfer and mixing performances. IPWP configuration is then introduced by manipulating the winglets' geometry and orientation of the reference case represented by DWP configuration.

IPWP vortex generator shows better performance when compared to the DWP case, taken to be the reference configuration, over a wide range of Reynolds numbers from laminar to turbulent. The IPWP peak friction magnitude is 50\% less than that in the DWP. Also the IPWP vorticity is increased by a value of $30 \%$ relative to the DWP configuration. Thus the thermal enhancement factor combining the heat transfer increase and the decrease in pressure loss is enhanced by about $6 \%$ in the case of the IPWP. This enhancement occurred due to the different vortex generation mechanisms exhibited by the IPWP. The number of vortices created by each pair of VG is six for the DWP case and it reaches ten for the IPWP one. The addition of those vortices positively altered the heat exchange process through the helical flow interaction between them. Thus the present results are very promising as the thermal 

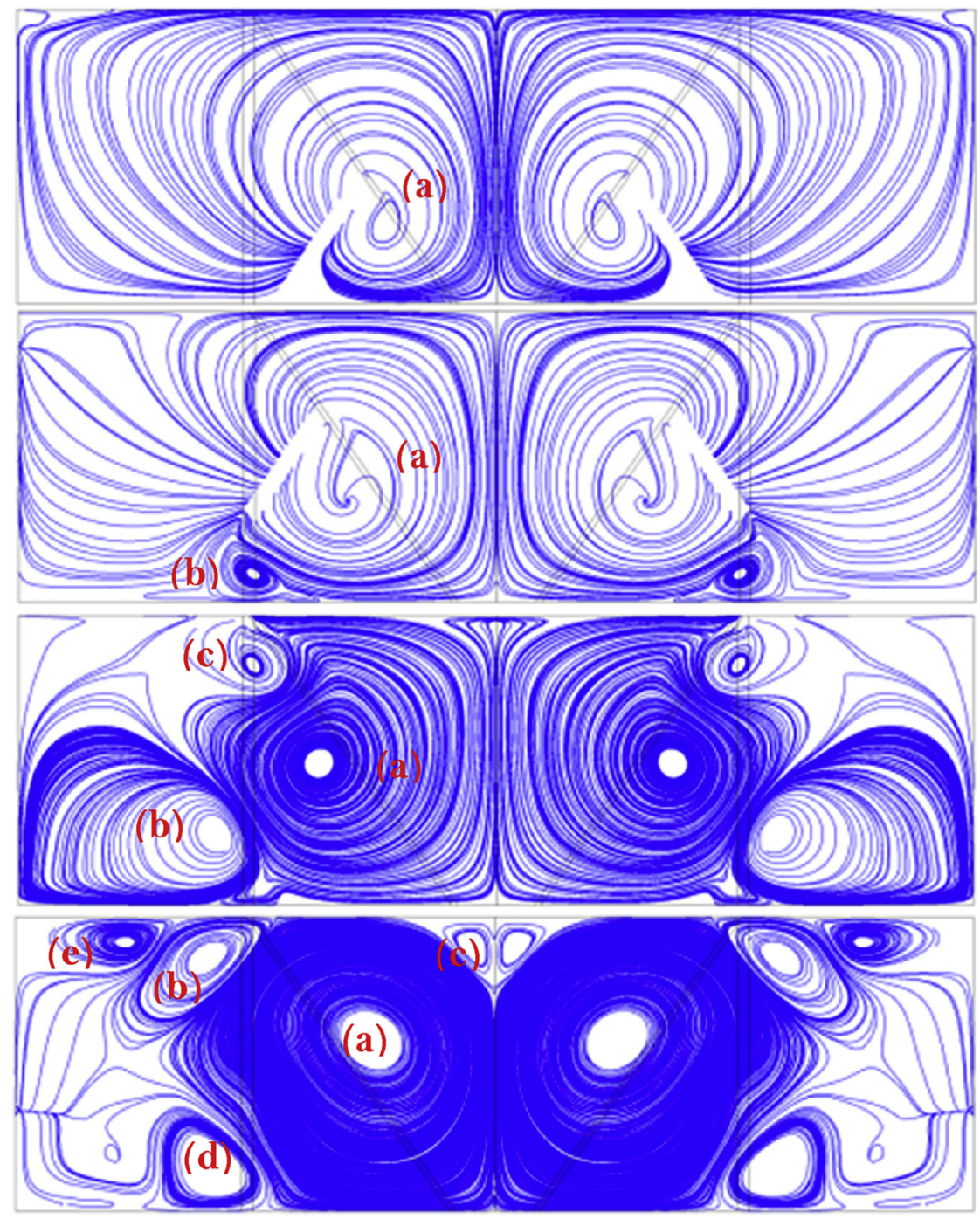

Fig. 10. Vortices developing mechanism for the IPWP at $x / H=2.5,3,3.5$ and 8 from velocity inlet.

enhancement factor is found to be increased 6\% for IPWP vortex generator compared to DWP case.

\section{References}

[1] Lin J. Review of research on low-profile vortex generators to control boundary-layer separation. Prog Aerosp Sci 2002;38:389-420.

[2] Islam MR, Hossain MA, Mashud M, Tanvir M. Drag reduction of a car by using vortex generator. Int J Sci Eng Res 2013;4(7).

[3] Ghanem A, Lemenand T, Della Valle D, Peerhossaini H. Static mixers: mechanisms, applications, and characterization methods - a review. Chem Eng Res Des 2014;92(2):205-28.

[4] Hatami M, Ganji D, Gorji-Bandpy M. Experimental investigations of diesel exhaust exergy recovery using delta winglet vortex generator heat exchanger. Int J Therm Sci 2015;93:52-63.

[5] Biswas G, Torii K, Fujii D, Nishino K. Numerical and experimental determination of flow structure and heat transfer effects of longitudinal vortices in a channel flow. Int J Heat Mass Transf 1996;39(16):3441-51.

[6] Webb R, Kim N. Principles of enhanced heat transfer. New York: Wiley; 1994.

[7] Chang SW, Lees AW, Chang H-T. Influence of spiky twisted tape insert on thermal fluid performances of tubular air-water bubbly flow. Int J Therm Sci 2009:48:2341-54.

[8] Gül H, Evin D. Heat transfer enhancement in circular tubes using helical swirl generator insert at the entrance. Int J Therm Sci 2007;46:1297-303.

[9] Elyyan MA, Tafti DK. A novel split-dimple interrupted fin configuration for heat transfer augmentation. Int J Heat Mass Transf 2009;52:1561-72.

[10] Habchi C, Russeil S, Bougeard D, Harion JL, Lemenand T, Della Valle D, et al. Enhancing heat transfer in vortex generator-type multifunctional heat exchangers. Appl Therm Eng 2012:38:14-25.

[11] Tala J, Russeil S, Bougeard D, Harion J-L. Numerical analysis of the fin spacing effect on the horseshoe vortex system evolution in a two-rows finned-tube heat exchanger. Int J Numer Methods Heat Fluid Flow 2013;23(7):1136-54.

[12] Vintrou S, Bougeard D, Russeil S, Nacereddine R, Harion J-L. Quantitative infrared investigation of local heat transfer in a circular finned tube heat exchanger assembly. Int J Heat Fluid Flow 2013;104:197-207.

[13] Garcia A, Solano J, Vicente P, Viedma A. The influence of artificial roughness shape on heat transfer enhancement: corrugate tubes, dimpled tubes and wire coils. Appl Therm Eng 2012;35:196-201.

[14] Wang J, Zhao Y. Heat and fluid flow characteristics of a rectangular channel with a small diameter circular cylinder as vortex generator. Int J Therm Sci 2015;92:1-13.

[15] Habchi C, Lemenand T, Della Valle D, Peerhossaini H. Turbulence behavior of artificially generated vorticity. J Turbul 2010:11(36):1-28.

[16] Khoshvaght-Aliabadi M, Zangouei S, Hormozi F. Performance of a plate-fin heat exchanger with vortex-generator channels: 3D-CFD simulation and experimental validation. Int J Therm Sci 2015;88:180-92.

[17] Wu J, Tao W. Numerical study on laminar convection heat transfer in channel with longitudinal vortex generator. Part B: parametric study of major influence factors. Int J Heat Mass Transf 2008;51:3683-92.

[18] Saha P, Biswas G, Sarkar S. Comparison of winglet-type vortex generators periodically deployed in a plate-fin heat exchanger - a synergy based analysis. Int J Heat Mass Transf 2014;74:292-305.

[19] Habchi C, Harion JL, Russeil S, Bougeard D, Hachem F, Elmarakbi A. Chaotic mixing by longitudinal vorticity. Chem Eng Sci 2013;104:439-50.

[20] Habchi C, Lemenand T, Della Valle D, Al Shaer A, Peerhossaini H. Experimental study of the flow field behind a perforated vortex generator. J Appl Mech Tech Phys 2015;16:221-9.

[21] Li L, Du X, Zhang Y, Yang L, Yang Y. Numerical simulation on flow and heat 
transfer of fin-and-tube heat exchanger with longitudinal vortex generators Int J Therm Sci 2015:92:85-96.

[22] Biswas G, Mitra N, Fiebig M. Heat transfer enhancement in fin-tube heat exchangers by winglet type vortex generators. Int J Heat Mass Transf 1994;37(2):283-91.

[23] Deb P, Biswas G, Mitra N. Heat transfer and flow structure in laminar and turbulent flows in a rectangular channel with longitudinal vortices. Int J Heat Mass Transf 1995;38(13):2427-44.

[24] Kamboj R, Dhingra PS, Singh PG. CFD simulation of heat transfer enhancement by plain and curved winglet type vortex generators with punched holes. Int Eng Res General Sci 2014;2(4).

[25] Zhou G, Feng Z. Experimental investigations of heat transfer enhancement by plane and curved winglet type vortex generators with punched holes. Int Therm Sci April 2014;78:26-35.

[26] He J, Liu L, Jacobi AM. Air-side heat-transfer enhancement by a new winglettype vortex generator array in a plain-fin round-tube heat exchanger. J Heat Transf July 2010;132. pp. 071801-1 till 071801-9.

[27] He Y, Han H, Tao YZWQ. Numerical study of heat-transfer enhancement by punched winglet-type vortex generator arrays in fin-and-tube heat exchangers. Int J Heat Mass Transf 2012;55:5449-58.

[28] Wu J, Tao WQ. Investigation on laminar convection heat transfer in fin-andtube heat exchanger in aligned arrangment with longitudinal vortex generator from the viewpoint of field synergy principle. Appl Therm Eng 2007;27: 2609-17.

[29] Herpe J, Bougeard D, Russeil S, Stanciu M. Numerical investigation of local entropy production rate of a finned oval tube with vortex generators. Int ] Therm Sci 2009;48:922-35.

[30] Fiebig M. Embedded vortices in internal flow: heat transfer and pressure loss enhancement. Int J Heat Fluid Flow 1995;16(5):376-88.

[31] Tiggelbeck S, Mitra N, Fiebig M. Flow structure and heat transfer in a channel with multiple longitudinal vortex generators. Exp Therm Fluid Sci 1992;5(4): 425-36.

[32] Ghanem A, Habchi C, Lemenand T, Della Valle D, Peerhossaini H. Energy efficiency in process industry - high-efficiency vortex (HEV) multifunctional heat exchanger. Renew Energy 2013;56:96-104.

[33] Fiebig M. Vortex generators for compact heat exchangers. J Enhanc Heat Transf 1995;2(1-2):43-61.

[34] Tian L, He Y, Lei Y. Numerical study of fluid flow and heat transfer in a flat plate channel with longitudinal vortex generators by applying field synergy principle analysis. Int Commun Heat Mass Transf 2009;36(2):111-20.

[35] Jain A, Biswas G, Maurya D. Winglet-type vortex generators with commonflow-up configuration for fin-tube heat exchangers. Numer Heat Transf Part A 2003;43:201-19.

[36] I. ANSYS. Turbulence models. ANSYS fluent 12.0 theory guide. April 2009. p. 27.

[37] Menter F. Two-equation eddy-viscosity turbulence models for engineering applications. AIAA 1994:32:1598-605.

[38] I. ANSYS. Standard and SST k-w models. ANSYS fluent 12.0 theory guide. April 2009. p. $131-5$.

[39] Yongsiri K, Eiamsa-ard P, Wongcharee K, Eiamsa-ard S. Augmented heat transfer in a turbulent channel flow with inclined detached-ribs. Case Stud Therm Eng 2014;3:1-10.

[40] Tanga X-Y, Zhu D-S. Flow structure and heat transfer in a narrow rectangular channel with different discrete rib arrays. Chem Eng Process Process Intensif 2013;69:1-14.

[41] Warming R, Beam R. Upwind second-order difference schemes and applications in aerodynamic flows. AIAA J 1976;14(9). pp. 1241-2149.

[42] Nacer-Bey M, Russeil S, Baudoin B. PIV visualizations to the flow structure upstream of the tubes in a two-row plate-fin-and-tube heat exchanger. In: Proceeding of the 4 th International conference on compact heat exchangers and enhancement technology for the process Industries, Grete Island, Greece; September 29-October 3, 2003. p. 63-8.

[43] Versteeg H, Mallasekera W. Computational fluid Dynamics. London: Longman Group; 1995.

[44] Zikanov O. Essential computational fluid Dynamics. Hoboken: Wiley; 2010.

[45] Naphon P, Kornkumjayrit K. Numerical analysis on the flow and heat transfer in the channel with V-shaped wavy lower plate. Int Commun Heat Mass Transf 2008;35:839-43.

[46] Bejan A, Kraus A. Heat transfer handbook, vol. 1. New Jersey: Wiley; 2003. p. 395-438.

[47] Tiggelbeck S, Mitra NK, Fiebig M. Comparison of wing-type vortex generators for heat transfer enhancement in channel flows. J Heat Transf 1994;116: $880-5$.

[48] Jeong J, Hussain F. On the identification of a vortex. J Fluid Mech 1995;285: $69-94$ 